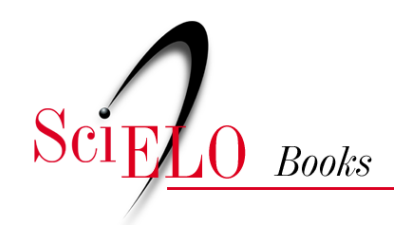

\title{
Capacidad criminal
}

\author{
Carol Iván Abaunza Forero \\ Mónica Alexandra Mendoza Molina \\ Paola Bustos Benítez \\ Giovanny Paredes Álvarez \\ Karla Vanessa Enriquez Wilches \\ Andrea Carolina Padilla Muñoz
}

\section{SciELO Books / SciELO Livros / SciELO Libros}

ABAUNZA FORERO, C.I., MENDOZA MOLINA, M.A., BUSTOS BENÍTEZ, P., PAREDES ÁlVAREZ, G., ENRIQUEZ WILCHES, K.V., and PADILHA MUÑOZ, A.C. Capacidad criminal. In: Adultos mayores privados de la libertad en Colombia [online]. Bogotá: Editorial Universidad del Rosario, Instituto Rosarista de Acción Social - SERES, 2014, pp. 218-239. ISBN 978-958-738-532-8. https://doi.org/10.7476/9789587385328.0009.

All the contents of this work, except where otherwise noted, is licensed under a Creative Commons Attribution 4.0 International license.

Todo o conteúdo deste trabalho, exceto quando houver ressalva, é publicado sob a licença Creative Commons Atribição $\underline{4.0}$.

Todo el contenido de esta obra, excepto donde se indique lo contrario, está bajo licencia de la licencia Creative Commons $\underline{\text { Reconocimento } 4.0 .}$. 


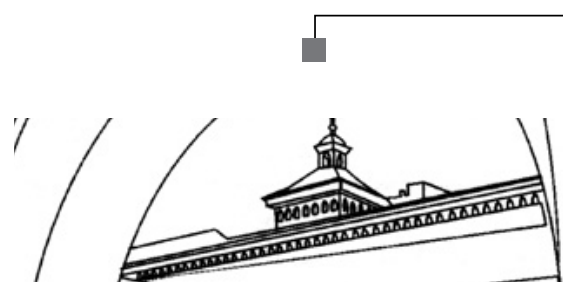




\section{Capacidad criminal}


El análisis propuesto para este apartado toma como referencia la información recabada de los internos que participaron en los grupos focales y busca poner en contexto las percepciones acerca de las razones por las cuales los adultos mayores cometen delitos, motivos para la reincidencia y la función del tratamiento penitenciario tanto en estos dos tópicos como en la convivencia diaria.

En Colombia se ha convertido en un hábito legislativo reformar el CP y sus afines, como el Código de Procedimiento Penal y el propio Código Penitenciario, bajo el prurito de atajar la criminalidad y la delincuencia. Estas reformas han ampliado el tiempo de condena de la mayoría de los delitos, han penalizado nuevas conductas y también han reducido beneficios. Esta política del Estado parece haber arrojado un creciente hacinamiento en las cárceles (Inpec, 2013). A juzgar por esta maximización del régimen punitivo, pareciese que el Estado colombiano no tuviese más instrumentos para solucionar los problemas de conflictividad social y económica (Barreto \& Sneider, 2009).

Encontrar respuestas que permitan comprender las actuaciones de las personas que cometen delitos es una constante en el campo de la investigación y prevenir conductas a futuro, una de las metas. Una prueba de ello es la normatividad que contempla la resocialización de los infractores de la ley penal mediante actividades de tratamiento, como es el caso del Código Penitenciario y Carcelario (Congreso de Colombia, 1993). Lograr este objetivo contempla la necesidad de conocer aspectos personales, sociales, familiares o institucionales de los infractores, para proponer acciones de resocialización cercanas a las realidades de los internos.

Como el segmento de la población carcelaria que motivó esta investigación son los AM, se procede a realizar un análisis de la capacidad criminal en internos que participaron en grupos focales realizados en diferentes EPC del país, con indagaciones acerca de las razones por los cuales cometen delitos y reinciden, y las alternativas de tratamiento penitenciario que ayudarían a prevenir la reincidencia en los AMPL. Los resultados se exponen a continuación. 


\section{Razones por las cuales los adultos mayores cometen delitos}

En las participaciones se observa que los AMPL mencionaron ejemplos o situaciones con las que explicaron su estadía en la cárcel, pero no la acción delictiva. En este sentido, el delito se presentaría como una oportunidad, como una única salida que liberaría de culpa a los condenados. Señalan aspectos personales relacionados con el uso y abuso del alcohol: "nadie está libre de que le pase y, isabe qué es lo que da más odio hoy en día?, que por el alcoholismo este aquí, donde yo no hubiera estado borracho no estuviera aquî" (grupo focal, EPMSC Bucaramanga, julio de 2013). Una de las participaciones generalizó al consumo de alcohol como la principal causa de la comisión de los delitos en AMPL: "por el alcoholismo es que la mayoría está aquî" (grupo focal, EPMSC Bucaramanga, julio de 2013). Para estos internos las situaciones que enmarcan el consumo de alcohol son las que desencadenaron las consecuencias jurídicas que actualmente enfrentan. También se hicieron referencias a los delitos efectivos o potenciales, que pueden estar relacionados con las diferentes etapas del proceso de las sustancias psicoactivas: producción, distribución, cambio y consumo.

El tema de la droga es una constante en varios de los discursos de los AMPL. Muchos de ellos han estado involucrados en esta problemática como consumidores, distribuidores, transportadores o fabricantes, o tienen algún miembro de la familia vinculado a estas actividades. También afirmaron que los delitos están aumentando con el paso del tiempo, debido a que la juventud tiene muchos problemas de uso y abuso de sustancias psicoactivas lícitas e ilícitas. Otros manifestaron que en sus casas se guardaba la droga, pero que ellos no tenían nada que ver con el asunto. Finalmente, hubo quienes afirmaron que la distribución y el transporte de drogas representaron una oportunidad para generar ingresos y garantizar la supervivencia. En otro caso, se evidencia cómo en las estructuras delictivas relacionadas con el narcotráfico la corrupción facilita el ejercicio de la comercialización y estimula la persecución al consumidor: "me veían ahí consumiendo drogas y encontraban al vendedor y a ese no lo cogían porque les daba plata a los policías y entonces por cumplir con la misión recogían cualquier 'chirrete', 
iy tenga!, yo estaba ahí, y me decían que yo traía más de lo que tenía. Ellos se aprovechan de esa situación para cargarse a la gente, solo por ser viciosos" (grupo focal EPMSC Cali, julio de 2013).

Esta participación ilustra un panorama en el que aparece el poder corruptor del dinero para exculpar a quien comete un delito, inculpando a quien padece una enfermedad como la adicción. De todo esto, se puede concluir que la droga y todos los procesos y efectos asociados a esta son determinantes para el abordaje del delito y reflejan una aguda problemática social que ha sido nombrada y reconocida por muchos de los AMPL, en varios de los temas que se abordaron en los grupos focales.

Otro de los tópicos se refiere a la teoría del autocontrol, en la que para explicar el delito, se muestra que en los individuos el autocontrol no puede observarse directamente aunque sí en sus manifestaciones y consecuencias (Serrano, 2011). En este sentido, algunos participantes declararon situaciones en las que se puede inferir que está presente ese factor: "resulta que me tocó matar a un señor porque no le fie un corte de cabello, era un ladrón, y yo le dije muchas veces que no lo podía peluquear, que yo tenía que pagar arriendo" (grupo focal, EPMSC Acacias, julio de 2013). En este relato se pueden observar efectos del bajo autocontrol. Un desequilibrio entre lo que el interno menciona como causa y la consecuencia que trajo tanto para la víctima como para el victimario. Otra participación se relacionó con esta característica: "Llegó el caso de estar tantos años sufriendo y luchando que salí por ahí a buscar unos materiales para mi trabajo, y por casualidad nos encontramos de frente y cuando ellos se me lanzaron de frente a pelear por lo mío tuve que matar a uno y bueno, el otro se salvó de milagro" (grupo focal, EPMSC Bucaramanga, julio de 2013). En estos casos se proponen situaciones en las que más que, explicar el delito, se justifica la ocurrencia como algo inevitable.

Los participantes expusieron una serie de explicaciones por las cuales los AM cometen delitos. Entre estas se identificó una gran cantidad de pensamientos que los libera de responsabilidad de la acción delictiva, proponiéndola como una conducta justificable. "Yo creo que sicológicamente todos tenemos el ego y desde que nacimos lo hemos estado alimentando negativamente y entonces nosotros de tercera edad tenemos ese ego hasta 
que muramos y eso lo obliga a uno a hacer cosas por costumbre" (grupo focal, EPMSC Bucaramanga, julio de 2013). En esta afirmación se explica el delito por una entidad que el participante denomina "ego", que es afirmado negativamente a través del tiempo y es el que determina la conducta. Otro interno manifestó que

[...] en ese sentido, se explicaría por qué hay dos cosas en la vida, una que se llama sino y otra que es el destino, ustedes entienden eso mejor que yo. El sino es lo que debe sucederse que está para sucederse, que se sucede aceptando, y el destino ya se lo forma uno, se lo hace se lo construye, y tal vez el sino nos traicionó en la primera oportunidad, pasó lo que tenía que suceder y sucedió. (Grupo focal, EPMSC Bucaramanga, julio de 2013)

En la anterior afirmación el motivo del delito se atribuye a una traición del sino y este es inapelable. Mientras que el destino se asoció con la decisión propia y esta no la relacionó con lo sucedido. Otras participaciones invirtieron el rol del AMPL, poniéndolo en el lugar de víctima de otras personas o situaciones, asociando el motivo de encarcelamiento con características de ingenuidad asociadas con la niñez: "el adulto mayor es muy fácil de convencer, igual que un niño. Uno tiene mucha sensibilidad y de pronto queda uno involucrado en cosas que no deben ser" o "por engaño, uno hace cosas que no debe" (grupo focal, EPMSC ERE Cali, julio de 2013). En estas afirmaciones continúa la tendencia a observar la responsabilidad del delito como algo ajeno a sí mismo.

Aportes realizados por los AMPL se centraron en minimizar las razones para la comisión del delito, y se llegó incluso a exculparlos mediante generalizaciones: "cualquier persona puede cometer un delito" (grupo focal, EPMS ERE Medellín, julio de 2013). Al parecer en esta ocasión existió el deseo de evitar la rotulación del AMPL como delincuente. Se observó también la propensión a homologar el acto delictivo con errores cotidianos: "aunque los que no han cometido ningún delito han cometido errores, quién no comete un error" (grupo focal, EPMS ERE Medellín, julio de 2013) o "todos cometemos errores sea de una u otra manera, pero cometemos errores y 
los cometemos una vez en la vida" (grupo focal, EPC Cojam, Jamundí, julio de 2013).

Una de las teorías que soportan el origen de la delincuencia está asociada a los procesos de aprendizaje y socialización de la conducta delictiva mediante la cual se llega a afirmar que todas las personas pueden delinquir y todo depende de la interacción del sujeto con las instituciones que forman su sociedad (Eduforma, 2012). En relación con esta postura, se manifestaron aseveraciones respecto a que en todas las esferas se presentan conductas delictivas, tanto en el ámbito público como en el privado, la diferencia es la forma como se tratan los delincuentes de "cuello blanco", respecto a los delincuentes de "overol".

Pero más allá de la reducción a la desigualdad en el trato, se puede vincular la historia familiar como formadora o no de la comisión del delito: "Pues que nadie está a salvo de cometer delitos, pero muchas veces el delito de uno no es que lo cometa uno, sino que la misma familia de uno se busca sus problemas. Pero no es porque verdaderamente uno lo haya cometido" (grupo focal, EPMS ERE Bucaramanga, julio de 2013). Por otra parte, se hace necesario mencionar prácticas familiares en las que existe tendencia a validar el quebrantamiento de la norma o de la ley; "hay personas que son muy desadaptadas, pero por qué, por malos padres, por la crianza" (grupo focal, EPMSC Medellín, julio de 2013), y como producto de la exposición a estas conductas, la percepción del delito se normaliza. Complementario a esto, los AMPL también explican la comisión de delitos a causa de la influencia del grupo social; en este sentido, las malas amistades, las costumbres y buscar obtener un estatus delictivo originan y preservan la conducta criminal.

Desde las explicaciones que se pretenden dar a las causas del delito entre los AMPL, la mayoría se centran en que se cometió el delito por necesidad: "en este caso, en la mayoría de las cárceles o centros se ve mucho el que llega por hurto, por la necesidad" (grupo focal, Coiba, Ibagué, julio de 2013). A esta condición está asociado el delito de hurto y las justificaciones giran en torno a ayudar a sus hijos, en especial las mujeres; además, en esta etapa de la vida se incluyen otras personas dentro del núcleo familiar para mantener que son los nietos: "un hijo pidiendo comida y uno no poder llegar a la casa y decir: no tengo para la leche de mi hijo, mi señora está 
aguantando hambre. Esa persona si no delinque a lo mejor se prostituye por las necesidades" (grupo focal, EPMSC Acacias, julio de 2013). Estas situaciones ponen de manifiesto una tensión entre las aspiraciones que los internos participantes tienen con respecto de las necesidades y las pocas oportunidades que observan para satisfacerlas. En ese sentido, Durkheim (citado en Soria \& Sáiz, 2006) afirma que en caso de que las primeras (aspiraciones) no puedan realizarse mediante oportunidades legítimas, se emplearán para ello métodos no convencionales. Otra de las justificaciones al delito es el consumo de sustancias psicoactivas: "el señor por consumir su vicio entonces comete ese delito que es lo que más se ve en las cárceles" (grupo focal, Coiba Ibagué, julio de 2013). En esta etapa aún se mantiene tal práctica y la dependencia a las diferentes sustancias conlleva nuevamente a que el delito de hurto sea el utilizado para adquirir la droga.

Dentro de este apartado resulta interesante analizar el rol dentro de la conducta delictiva; una proporción de AMPL dentro de la narración de los hechos materia de sanción esgrimen historias que pueden ser calificadas como increíbles si se aplican principios lógicos para su interpretación y comprensión: "Yo me dejé convencer de un tipo naturista que sembraba unas pepas y salió marihuana, y me las dio para que se las vendiera y las tenía en la casa como planta medicinal" (grupo focal, EPMS ERE Bucaramanga, julio de 2013). Las coincidencias presentadas en los testimonios están en el papel de víctima, exponiendo a manera de insinuaciones la ingenuidad o carencia de conocimientos como las razones para la comisión del delito.

También existen tendencias a observar a los AM como personas con menor capacidad para delinquir o reincidir aunque las carencias económicas, limitaciones al mercado laboral y las condiciones de vida son de un elevado nivel de riesgo (Williams et al., 2012), y es una realidad que sean utilizadas por la facilidad que esta percepción ofrece para desviar posibles sospechas. Las limitaciones físicas conducen a desempeñar acciones que no tengan implicación de esfuerzo, con prácticas generalmente asociadas a delitos por estupefacientes, especialmente el porte, el microtráfico o la receptación.

El fenómeno de la comisión de delitos sexuales por parte de AM es el más generalizado. Según datos del Inpec, a la fecha del 31 de julio de 2013, el 47,58 \% de los AMPL están por este delito. Seguido se encuentra el tráfico 
de estupefacientes con un 14,42\% y homicidio con el 13,55\%. Dentro del trabajo de campo, un hecho presentado es la negación del delito sexual ante personas externas, pero también por su integridad en el interior de la cárcel. Sin embargo, otras personas condenadas por este mismo delito sí lo manifestaron abiertamente; lo que llama la atención es escuchar la justificación del delito: "Yo no me siento orgulloso de que me hayan condenado por ese delito, pero tampoco me avergüenzo porque lo mío fue con una mujer que estaba viviendo con una señora, llegó la hija y vio las buenas condiciones..., entonces la muchacha vio las condiciones y empezó a metérseme, y las tentaciones de uno... iLa carne es jodida!" (grupo focal, Cocuc Cúcuta, julio de 2013). Se desplaza la culpabilidad a la víctima indicando insinuación y preparación del delito por parte de esta con el fin de conseguir algo, pero también se presenta a la víctima como un estímulo imposible de controlar. Así, la consumación del delito es justificada, como algo ocasional o de oportunidad.

Desde los factores sociales, los AMPL en sus narraciones hacen mayor énfasis en la falta de oportunidades laborales como fuente del delito; en este orden, existen dos planos que lo sustentan: la edad como limitación o impedimento para la consecución de un trabajo "porque a una de 40 años en adelante no le dan trabajo en ninguna parte, entonces uno se pone a hacer cosas que uno no cree llegar hasta aquî" (grupo focal, Coped Medellín, julio de 2013) y la ignorancia vista como ausencia de algún conocimiento. Muchos afirman haber delinquido por desconocimiento o por no tener herramientas para discernir entre lo que está bien y lo que no.

En este punto, vale la pena mencionar que algunos AMPL afirman no saber leer y escribir o no haber recibido educación alguna al momento de la comisión del delito y de la captura; por lo tanto, se recalca la importancia que se otorga a los conocimientos adquiridos en los programas de tratamiento penitenciario, reiterando que de no ser por estos programas no habría otras oportunidades de acceder a la educación. "El adulto mayor, por lo general, en el caso principal mío comete errores, los he cometido y de pronto los esté cometiendo, pero es por falta de estudio" (grupo focal, EC Bogotá, julio de 2013). Existen condiciones sociales de desigualdad, pobreza y vulneración que también fueron consideradas por los AMPL: 
Antes violaron mis normas, mis derechos y por eso me encarcelaron, uno como persona debe mirar y definir a qué capa social pertenece y se une con ella..., con la presión que viene de hace mucho tiempo de la violencia y eso, entonces no lo dejan a uno, uno ve que al compañero lo mataron, que al otro también, entonces necesariamente uno se ve presionado y le toca coger otro camino para seguir luchando, porque es mejor morir de pie que vivir toda la vida arrodillado. (Grupo focal, Complejo Penitenciario y Carcelario de Ibagué, junio de 2013).

Otros testimonios en este mismo sentido apuntan a un choque contra las estructuras del Estado, que convierte a los individuos en amenazas para la sociedad y el orden establecido. Como se ha notado, la "necesidad" es según los participantes la principal causa del delito y en torno a un cúmulo de necesidad se hicieron alusiones a la familia, los niños, la enfermedad, el hambre y la falta de trabajo. En efecto, muchos testimonios evidencian las precarias condiciones de vida y la suma de muchas vulnerabilidades, que en ocasiones desembocan en la comisión del delito como alternativa de supervivencia; sin embargo, existen estudios como los de Cohen y Felson (citados en Garrido et al., 2001), que les permite afirmar que la mejora de las condiciones de vida de la gente en términos de eliminación de pobreza, aumento de la escolarización y del empleo no tiene relación directa con la disminución de la delincuencia.

Como se observó, en la mayoría de los casos, los AMPL afirman ser inocentes, haber sido mal condenados, culpan al sistema de justicia y a sus diferentes actores, es decir, no reconocen el delito, no entienden la pena o esta última no es aceptada por considerarse injusta. Muy pocos reconocen haber delinquido, muy pocos se muestran arrepentidos, muy pocos reconocen el daño que pudieron ocasionarle a terceros y solo un mínimo reconoce la funcionalidad de la prisión. Como consecuencia de la negación del delito, se imputa la privación de la libertad al sistema de justicia. Desde esta perspectiva, no hay un delito como tal, pero sí se imprime un castigo; por lo tanto, no hay causas del delito, sino de la pérdida de libertad, que en muchas ocasiones se atribuyen a la mala administración de la justicia, la corrupción y ejercicios de poder en los cuales ellos son las víctimas. 
Sin dejar de lado lo anterior, es necesario visibilizar que también resultan afectados por dos fenómenos sociales actuales del país, el desplazamiento: "soy una persona desplazada y tenía seis hijos, entre ellos yo tenía cuatro menores, al papá lo mató la guerrilla, yo no tenía otra alternativa” (grupo focal, Cojam Jamundí, julio de 2013) y la desigualdad social: "yo diría que las condiciones varían de acuerdo con la condición social, uno por la desigualdad, la pobreza y el otro por la situación que vivimos, el vicio, entre las dos hay delincuentes" (grupo focal, Coiba Ibagué, julio de 2013). El primero está presente principalmente en las mujeres y el segundo es manifestado más por los hombres. En este orden de ideas, la génesis del delito en AMPL también es producto de consecuencias sociales de otros delitos, como el conflicto armado y la corrupción, que deben ser estudiados en profundidad y de manera específica desde la perspectiva de género, orden social y delito.

\section{Razones para la reincidencia}

Maximizar el uso del régimen punitivo demanda crecientes recursos públicos, sin que se obtengan resultados claros sobre el beneficio que esta política tiene a corto, mediano y largo plazo para la sociedad. No es claro que las cárceles produzcan reinserción social a quienes las habitan sin importar el tiempo que dure el encarcelamiento, toda vez que en Colombia la reincidencia de reclusos condenados es creciente y el endurecimiento de las penas ha sido una política deliberada. Según datos del Inpec, se registra un incremento de 1771 reclusos reincidentes, al pasar de 9244 en diciembre de 2003 a 11015 en abril de 2008 (Barreto \& Sneider, 2009). La reincidencia se refiere a la repetición de un acto delictivo por parte del delincuente, hace parte de su comportamiento y alude a los estudios del delito y la criminología, como un elemento de la interacción social (Ossa López, 2012). En términos generales, se tiene como un agravante en el proceso penal, conforme a lo manifestado por la Corte Constitucional en sentencia C-077/2006 al referirse al artículo $55 \mathrm{del} \mathrm{CP}$. Aunque cosa diferente hubiese expresado la Corte Suprema de Justicia en el radicado 26149 del 18-05/2008. 
$\mathrm{Al}$ señalar el término como referencia a una persona que es objeto de una intervención judicial penal (pena) por reincidir (Unodc, 2012), y teniendo en cuenta que constituye un obstáculo para acceder a los beneficios sustitutivos de la pena privativa de la libertad, de la suspensión condicional de la ejecución de la pena (artículo 63 CP) y la prisión domiciliaria (artículo $38 \mathrm{CP}$ ), la reincidencia se convierte en un factor determinante para evaluar la efectividad del tratamiento penitenciario ofrecido a los internos. En este sentido, se indagaron en los participantes las razones por las cuales los AMPL vuelven a cometer delitos, y se encontró que están correlacionadas con las explicaciones de por qué se cometen delitos, en especial por la falta de oportunidades y la necesidad.

En relación con este cuestionamiento, los AMPL se centraron en dos focos principales: factores personales y factores sociales. En el primer factor indican los participantes que la reincidencia está condicionada a la edad, es decir, que observan con mayor probabilidad que las personas jóvenes vuelvan a cometer un delito y que las personas AM por su condición ya no lo hacen: "yo creo que reincide más la gente joven, por edad, por la falta de experiencia” o "ya no. Nosotras no. Las jóvenes" (grupo focal, RM Bogotá, julio de 2013). También se hace alusión al consumo de alcohol y otras drogas como posible detonante de actos delictivos, luego de haber estado condenado en prisión: "yo pienso en el tal ladrón, porque un muchacho de esos vive de eso y para sostener su vicio, si no consigue dinero van a volver a robar" (grupo focal, EPMSC ERE Bucaramanga, julio de 2013).

De igual manera, incluyen la oportunidad como factor de elección del delito: "la mayoría de nosotros no tenemos esa educación; si uno teniendo familia, papá y mamá, comete esos errores..., hacemos lo de Judas, nos bañamos las manos y decimos que no lo volvemos a hacer, pero si vemos la oportunidad..." (grupo focal, Cocuc Cúcuta, julio de 2013). Se puede entender que para estos participantes la reincidencia se presentará una vez se dé la confluencia entre ellos, las víctimas y la ausencia de eficaces protectores, nombrados por Cohen y Felson (citados en Garrido et al., 2001).

Dentro de los factores sociales se menciona de forma particular que la atribución es relacionada con el locus de control externo, definido como la tendencia del individuo a percibir su conducta como menos controlable 
porque las causas no dependen de sí (Azzollini \& Bail Pupko, 2012). En esta medida, sugieren la reincidencia como producto de la falta de acceso a la educación: "acá en Colombia le quitan el fuero a todo, a mi edad, nosotros no tuvimos la oportunidad de estudiar" (grupo focal, Cocuc Cúcuta, julio de 2013), por historia de vida o idiosincrasia: "bueno, un concepto personal, parte de la misma idiosincrasia, el papá de uno le dice que uno es una bestia..., esa manera de ellos pensar se la educaron a uno, uno puede llegar a donde no debe para salir a la realidad de la vida" (grupo focal, Cocuc Cúcuta, julio de 2013). Sin desconocer lo anterior, se hace necesario mencionar que aparecieron razones para la reincidencia asociadas a condiciones sociales evidentes en la realidad del país, como son las problemáticas de los conflictos armados internos, falta de vivienda y de educación, de las cuales señalan como responsable al Gobierno y el Estado.

Al fenómeno de la reincidencia le son adjudicadas causas disímiles por parte de los aMPL, especialmente centradas en la falta de oportunidades y el acoso de las necesidades. Solo un participante retomó la reincidencia como un fracaso en la resocialización: "yo creo que hay una parte virtual y la otra real, en la virtualidad de pronto informes de agencias y así para aparentar, pero a mí me parece que hay casos de gente que lleva cinco, seis y siete entradas, entonces el trato no se ha realizado para atacar el problema estructural" (grupo focal, EPMSC Bucaramanga, julio de 2013). Este discernimiento aborda el fracaso de un tratamiento penitenciario anterior y por ser la única afirmación relacionada con este aspecto como posible causa de la reincidencia pone de manifiesto que para la mayoría o no existe el tratamiento o no se percibe con los objetivos con los cuales ha sido postulado, tanto en ley como en la normatividad penitenciaria, con lo cual se confirma que las dificultades de acceso a educación, trabajo, salud física o mental truncan la inserción social y aumentan las probabilidades de reincidencia penal (Bravo \& Castrillón, 2010).

Más allá de quedarse en el bucle de si la cárcel mejora a las personas o las destruye, es necesario pensar en tratamientos diferentes para los primodelincuentes y para los reincidentes, por cuanto en los comportamientos delictivos de unos y otros se implican interacciones, pensamientos, elecciones, emociones, recompensas, rasgos y perfiles de personalidad, aprendizajes 
y socializaciones, creencias, actitudes, atribuciones, expectativas (Redondo $\&$ Pueyo, 2007), que exigen ampliar los marcos desde los cuales se analizan las necesidades de los internos, como esta en la que se observa la incertidumbre y la importancia del sistema familiar para lograr una reinserción exitosa: "que uno tenga certeza de que al salir no va a reincidir porque eso depende del sistema de vida que ha tenido, de la forma como vaya a salir, de si la familia está presente. Porque aquí "hay gente que tiene familia y no les permiten la entrada a la casa, hablo de muchas personas", "no, no, no aquí a la casa no venga” (grupo focal EPMSC Medellín, julio de 2013). Contrastar esta información obtenida de primera mano con los protagonistas, con la que se encuentra en las pautas, los procedimientos y las directrices del Inpec, deja la sensación de que las necesidades de los internos -contrario de ser incluidas mediante recolección de información estructurada, como resultado de investigaciones promovidas por las diversas subdirecciones del Inpec- parecen ser inferidas en relación con la experiencia de los profesionales que se encuentran a cargo de impartirlas desde un nivel central.

\section{Tratamiento penitenciario}

El tratamiento penitenciario en Colombia se define como:

[...] el conjunto de mecanismos de construcción grupal e individual, tendientes a influir en la condición de las personas, mediante el aprovechamiento del tiempo de condena como oportunidades, para que puedan construir y llevar a cabo su propio proyecto de vida, de manera tal que logren competencias para integrarse a la comunidad como seres creativos, productivos, autogestionarios, una vez recuperen su libertad. (Inpec, 2005)

Dichas estrategias se desarrollan mediante estudio, trabajo y enseñanza. Como se puede observar, con el tratamiento penitenciario se busca lograr cambios en las personas, sin definir particularidades por tener en 
cuenta de acuerdo con las características de los diversos grupos que forman la población privada de la libertad. Entre estos se encuentran los AMPL.

Estas acciones se han organizado teniendo en cuenta los principios del sistema progresivo, en una metodología denominada Plan de Acción y Sistema de Oportunidades (PASO), concebida como herramienta para organizar y articular cada uno de los mencionados componentes y fases de seguridad en el Tratamiento Penitenciario y la Atención Integral, en beneficio del interno(a) y su proceso de reinserción de manera progresiva (Universidad Nacional de Colombia, Inpec, 2008). Con esto se encontró que los AM condenados en su mayoría están en fase de alta seguridad. El porcentaje correspondiente a quienes aún no se encuentran clasificados en fase de seguridad y los que están en fase de observación, diagnóstico y clasificación suman un $48 \%$ de la población; es decir, casi la mitad de los AM condenados en Colombia no han iniciado su tratamiento penitenciario.

Figura 33. Población adulta mayor privada de la libertad por fase de tratamiento

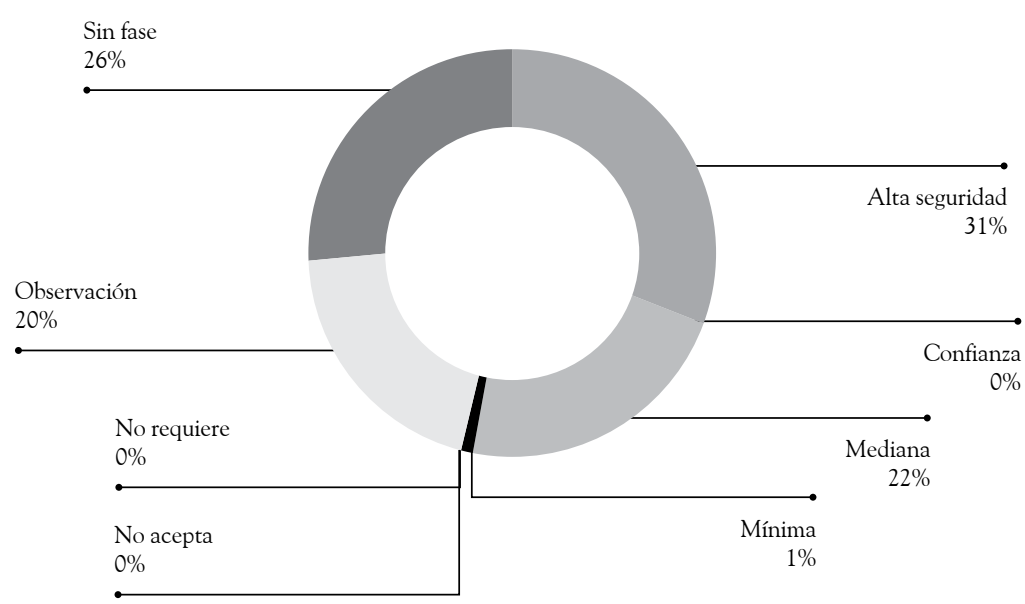

Fuente: Sisipec Web, 31 de julio de 2013. Cálculos de los autores.

Partiendo de la premisa que rige el tratamiento penitenciario, se encontraron percepciones que los AMPL tienen al respecto, máxime cuando han sido considerados como población en condiciones excepcionales (Subdirección de Reinserción Social Inpec, 2012), y aun cuando los participantes no estén relacionados con el término. La mayoría de participantes en los 
grupos focales no conocen qué es una población excepcional o no están relacionados con el término. Algunos de ellos lo asocian a la población LGBTI o a los pueblos indígenas, otros reconocen que se trata de poblaciones que tienen una especial protección de la ley, que se encuentran en riesgo o que requieren un tratamiento especial "excepcionales, como los indígenas", "los campesinos", "los que no tienen abogado", "los gais, los de la tercera edad" (grupo focal, EC Bogotá, julio de 2013). La precepción está asociada a la pertenencia a grupos minoritarios o con características diferenciales marcadas frente a la población en general. En el ámbito carcelario, se reconoce, por algunos de los participantes, que los AM hacen parte de las poblaciones excepcionales y que por tanto deben recibir un tratamiento diferente al de los demás internos. Dentro de los aspectos que se mencionan, asociados a este tipo de tratamiento, los más comunes son un patio exclusivo, una alimentación acorde a la edad, la posibilidad de una metodología de estudio especial que reconozca las condiciones físicas y mentales propias de los AM y la prioridad de atención en salud.

Los AMPL participantes asocian el tratamiento al estudio o capacitación formal y no formal, que reciben en el EPC, y uno de los que tiene acceso a este le otorga calificación positiva, manifestando agradecimiento por las cosas aprendidas en prisión. Se mencionan entonces las clases, las manualidades, los talleres y los oficios, haciendo referencia constante al aprovechamiento del tiempo y a la utilidad que se le dará a estos nuevos conocimientos, una vez se recupere la libertad. "Para mí es muy bueno porque cuando yo era pequeña mi mamá no pudo darme estudio, pero en la cárcel terminé mi primaria. No pude estudiar bachiller por cuestiones de salud, entonces no pude seguir con mi bachillerato..., quería seguir estudiando, pero no pude" (grupo focal de mujeres, Complejo Carcelario y Penitenciario de Jamundí, julio de 2013).

Se identificó la carencia de competencias lectoras y escritoras de los AMPL y la falta de oportunidades para acceder a capacitaciones o formación en su juventud. Esto puede incidir en que identifique el tratamiento con la formación y se afirme que la prisión trae algunos aprendizajes. Sin embargo, no se valora la capacidad resocializadora del tratamiento, sino la oportunidad que representa para redimir pena o la diferencia que ofrece frente 
a una vida anterior de privaciones. $\mathrm{Al}$ respecto, incluso se hacen bromas: "No, de haber sabido que iba a aprender tantas cosas, habría entrado antes ja, ja, ja," (grupo focal, EPMSC Bucaramanga, julio de 2013).

Las constantes menciones de ocupación en lo educativo y lo laboral cuando hacen alusión al tratamiento penitenciario visualizan la brecha existente entre la definición que se expuso por parte del Inpec y lo que los AMPL perciben de este: "Porque yo manejo los hilos, pero aprendí con eso a entretenerlos, pero aquí no hay alguien que diga: vengan muchachos hagamos esto, hagamos lo otro. No hay nada. Y si comienzan un proceso, vienen dos o tres días y no vuelven" (grupo focal EC Bogotá, julio de 2013). Conexo aparece el uso del término "resocialización" para referirse a la participación en actividades, mas no a un proceso que implica cambios personales:

[...] aquí no se resocializa a nadie, aquí se viene a aprender más mañas, que sí, que yo sé que salgo, no eso es mentira porque si por ejemplo yo soy un exportador aquí hay muchas personas. Aquí por ejemplo me dicen: vea se va a ganar $\$ 30.000 .000$ o $\$ 20.000 .000$ y yo en este momento con la situación que salgo, yo no me pongo a pensar tanto en la cárcel que me devuelvan porque necesito la plata, entonces aquí no hay resocialización. (Grupo focal, EPMSC Acacias, julio de 2013)

En este sentido, el tratamiento se ha convertido en un conjunto de actividades para entretener a los presos (Gil, 2010). En algunos casos las actividades resultan inexistentes, al tiempo que la redención de pena se certifica como efectiva, hecho que desdibuja aún más la orientación que debería tener el tratamiento penitenciario: "Sí, pero eso es simbólico porque nosotros eso no lo hacemos", "únicamente dice trabajo, nos llega una planilla que dice trabajo tanto tiempo, pero en realidad no se ve como trabajo" (grupo focal, EPMSC Acacias, julio de 2013).

Al indagar sobre el tipo de tratamiento que se recibe en prisión, la mayoría de AMPL afirmaron no recibir un tratamiento de tipo diferencial; por el contrario, enfatizaron en que el tratamiento es el mismo para todos y que no se adapta a las condiciones particulares de un AM. Lo que más se reclama en este sentido es un espacio exclusivo para AM, pues se afirma 
que los pabellones compartidos con otras poblaciones son extremadamente agresivos y facilitan la vulneración de esta población. "Allá se consume mucho vicio, hay muchos problemas y todo eso a uno ya le molesta por la edad, uno requiere más tranquilidad, más sosiego" (grupo focal, EPMSC Cali, julio de 2013). Algunos de los AMPL dicen haber sido víctimas de ataques, robos o malos tratos por parte de otros internos, que no respetan su edad ni su condición.

Así pues, pocos participantes tienen una valoración positiva del tratamiento penitenciario que reciben, afirmando que efectivamente está orientado a la resocialización o reconociendo que cualquier tipo de ocupación es necesaria en prisión, para pasar el tiempo y no desesperar. En general los participantes tienen una valoración negativa y no reconocen que el tratamiento pueda servir para la resocialización; por el contrario, afirman que la prisión es una verdadera "universidad del delito".

¡No sirve! Aquí el tratamiento que la cárcel le da al preso no resocializa a nadie; aquí de pronto el que no requiera resocialización se mantenga firme y no siga incurriendo, ni especializándose, pero las cárceles colombianas son una especialización del delito. Muchas personas que realmente no son delincuentes y por cualquier circunstancia caen a la cárcel se convierten en verdaderos delincuentes. Aquí no hay resocialización. (Grupo focal, EPMSC Cali, julio de 2013).

En consecuencia, pocos AMPL reconocen un cambio interno como resultado de su estancia en prisión y este no es atribuido al tratamiento, sino a largas jornadas de reflexión, a un enfrentamiento consigo mismos y a la superación de las adversidades y sinsabores propios del ámbito penitenciario.

El aspecto de tratamiento diferencial es entendido por los AMPL como un derecho al que pueden y deben acceder, por su condición de AM: "tienen que darnos un trato especial porque somos adultos mayores. En la cárcel no es lo mismo que nos vayan a tirar revueltos con los muchachos de $20 \mathrm{o}$ 25 , que nos pueden agredir y uno no puede defenderse igual" (grupo focal, Complejo Carcelario y Penitenciario de Jamundí, julio de 2013). Se reitera así que la solicitud primordial de los internos es un patio especial, aislado 
de otras poblaciones frente a las que se sienten amenazados o que manejan una escala de valores diferente a las suyas.

Las solicitudes muy puntuales de los internos se ubican perfectamente en el marco de los enfoques diferenciales, reconocidos y estipulados por la Ley 65 de 1993, en su artículo 3 A: "El principio de enfoque diferencial reconoce que hay poblaciones con características particulares en razón de su edad, género, orientación sexual y situación de discapacidad. Por tal razón, las medidas penitenciarias contenidas en la presente ley, contarán con dicho enfoque" (Congreso de Colombia, 1993).

Hablar de enfoques diferenciales en prisión inmediatamente remite a pensar en espacios adecuados para las necesidades específicas de las distintas poblaciones. Este razonamiento se fortalece aún más al tratarse de poblaciones de AM, de personas en condición de discapacidad o de personas con enfermedades crónicas, pues sus determinantes físicos y las limitaciones a la movilidad sin duda exigen un entorno amigable, que facilite su vida. De esta manera, los espacios deberían estar dotados de rampas, preferiblemente no tener escaleras, tener corredores amplios y garantizar tramos cortos entre los lugares donde se desarrolla la vida cotidiana (la celda, el baño, el patio, el comedor). Sin embargo, no se ha llegado a un consenso sobre la importancia de generar espacios especiales para estas poblaciones o adecuar todos los EPC con estas características. Lo cierto es que en la actualidad no hay espacios especiales en los EPC existentes y tampoco están dotados para facilitar la movilidad.

Un hecho que parecería obvio, en términos médicos, sociales y económicos, como la creación de establecimientos especiales para estas poblaciones, no lo es tanto para quienes toman las decisiones en materia penitenciaria. De esta manera, no hay una normativa internacional que recomiende los establecimientos especiales y tampoco hay muchos países que los estén implementando. Colombia no es la excepción y así los AMPL comparten su estadía en prisión con todos los demás reclusos, con algunas excepciones, como el pabellón de AM de EPMSC Cali (ERE), en el que sin duda se presentan dinámicas interesantes de autogestión y se evidencian prácticas en materia de calidad de vida acordes con la población. Este establecimiento puede presentarse como ejemplo claro de tratamiento diferencial a la 
población de AMPL: "Yo siento que aquí en este patio se viven cosas muy diferentes a otros patios, que están en hacinamiento y donde no duermen bien; nosotros aquí estamos viviendo una vida mejor. No hay hacinamiento, no hay encierro, aquí no se consume droga, no se pierden las cosas, no hay delincuencia" (grupo focal EPMSC Cali, julio de 2013).

Es pertinente en este punto precisar la diferencia existente entre el trato y el tratamiento, definiendo el trato como la forma de configurar las relaciones entre el interno y la guardia, y entre el interno y los demás internos. Al respecto, la mayoría de AM reconocen un buen trato por parte de la guardia, que se ve favorecido en los casos en los que se cuenta con un patio especial para ellos, dado que (como lo reconoce el personal de guardia) los AM no representan un gran riesgo para la seguridad, por lo que las relaciones con ellos tienden a disminuir la tensión: "Como le digo hay muchos..., pues digamos en ese tema de los guardianes, el personal de seguridad, para los que vivimos en este patio el trato es normal, dentro de lo normal" (grupo focal, Coiba Ibagué, julio de 2013).

Igualmente, las relaciones entre el interno y los demás internos son mucho más cordiales y llevaderas en estos espacios especiales aun en condiciones de hacinamiento, que cuando no se cuenta con ellos: "Pero desde que yo estoy aquí en este patio..., en este patio hay buena convivencia, relativamente. De pronto por ahí hay disgustos pero pasajeros, pero no pasan a mayores" (grupo focal, Coiba Ibagué, julio de 2013).

Cuando no se cuenta con un patio especial, la guardia mantiene un trato igual con todos los internos, sin consideraciones con el AM; de esta manera, se somete a todos a las mismas requisas y a las mismas rutinas:

Sí porque muchas veces en una requisa la verdad lo miran a uno mal, lo empujan $[\ldots]$ pero muchas veces el mismo trabajo que hacemos cuando hacen esas rascadas en los patios cuando se llevan las matas que hacemos, se llevan los cinturones que hacemos, entran los muchachos bachilleres y ellos llegan con orden del teniente y nos recogen todo se lo llevan y lo botan por allá y eso desaparece, no tenemos derecho a tener una pantaloneta para ponérnosla porque tiene que ser de tal color. (Grupo focal, EPMSC Acacias, julio de 2013) 
Lo anterior, sumado a la relación con los otros internos, complejiza la convivencia del AMPL, pues se manifiestan abusos precisos como el robo de objetos personales: "Uno sale pa' allá abajo con miedo porque a los viejos nos atracan, nos hacen de todo" (grupo focal, Complejo Carcelario y Penitenciario de Bogotá, julio de 2013), las agresiones físicas y verbales y el uso y abuso de sustancias psicoactivas, que se atribuyen mayormente a los internos más jóvenes.

Hay mucho consumo de vicio, la pelea, la riña y los jóvenes no son todos los que pelean, o que lo insultan y lo quieren agredir, pero sí hay uno que otro que lo trata por lo menos de agredir. Por ahí está el grupo de oración y lo tratan a uno de viejos hijue... no sé qué. Hay un trato verbal que ofende, pero como uno no puede ponerse a pelear con ellos porque pierde uno por la edad, porque ellos lo pueden herir a uno. (Grupo focal, Cocuc Cúcuta, julio de 2012)

En el tema de alimentación, se evidenció que hay una dieta especial para las personas hipertensas, que no necesariamente pertenecen al grupo de AM; por lo demás, las dietas son las mismas y también los demás aspectos. Como conclusiones se puede proponer el hecho de que los internos afirmen haber encontrado en la prisión oportunidades que no encontraron afuera. Se plantea una reflexión sobre la finalidad del tratamiento penitenciario, que por supuesto no es garantizar derechos que debieron ser garantizados afuera. Que la prisión tenga este significado para los AMPL permite en primer lugar cuestionar el rol del Estado como garante y como castigador. En segundo lugar, ofrece la posibilidad de analizar las ventajas de delinquir, sobre las posibilidades de no hacerlo en ciertos medios; finalmente, hablar de las bondades de estar en prisión por las ventajas que ofrece la satisfacción de necesidades básicas por parte de las instituciones carcelarias.

Las condiciones físicas de los AMPL son unas de las principales razones por la cuales se puede presentar la disminución en el riesgo de reincidencia, pero tanto la capacidad intelectual como las características individuales y condiciones sociales son cercanas a los factores de riesgo que favorecen las posibilidades de reincidencia en actos delictivos. 
Como variable del tratamiento penitenciario surgió el concepto de tratamiento diferencial, que hace referencia a las formas de discriminación de las que pueden ser víctimas los grupos minoritarios o poblaciones excepcionales y además busca brindar una atención acorde a los requerimientos de dichas poblaciones. Efectivamente, las rutinas en los pabellones destinados específicamente para AMPL son más flexibles: las celdas suelen estar abiertas, no hay un horario estricto para levantarse ni para acostarse y hay más posibilidad de movilidad. Esto puede responder a que no se percibe en los AMPL una amenaza latente, de hecho, los guardias hacen referencia a que allí nunca ocurre nada y hacen bromas relativas a la "peligrosidad" de los internos que allí se alojan, incluso se refieren a ellos como "perros viejos".

La ausencia de intervenciones diseñadas para las problemáticas psicosociales manifestadas por los AMPL y de personal capacitado en la atención de estas personas pone de manifiesto la tendencia de los EPC y del Inpec en general a implementar acciones que distan de la realidad cotidiana, lo cual dificulta el hecho de que un AMPL pueda experimentar adherencia en un proceso de tratamiento, ya que una persona no puede ni debería adecuarse a lo que otros consideran conveniente para ella (Saenz, 2007). Al respecto, se encontró un estudio en el que se evidenció que los AMPL en promedio experimentaron más adherencia al tratamiento específico y un menor número de violaciones de libertad condicional que los adultos jóvenes, durante un seguimiento que se les hizo durante seis meses (Canada et al., 2013), que apoyan la necesidad de implementar acciones de tratamiento diferencial de acuerdo con las necesidades percibidas por los participantes y las que son producto de investigaciones estructuradas. 